\title{
UMA ANÁLISE DO ROMANCE AMOR DE PERDIÇÃO, DE CAMILO CASTELO BRANCO
}

\author{
ANALYSIS OF THE NOVEL LOVE OF PERDITION, BY CAMILO CASTELO \\ BRANCO
}

Recebido: 13/10/2021

Aprovado: $10 / 12 / 2021$

Publicado: 22/12/2021

DOI: $10.18817 /$ rlj.v5i2.2672

\author{
Erika Maria Albuquerque Sousa ${ }^{1}$ \\ Orcid ID: https://orcid.org/0000-0003-0561-8961 \\ Maria do Socorro Carvalho ${ }^{2}$ \\ Orcid ID: https://orcid.org/0000-0001-9647-0215 \\ Solange Santana Guimarães Morais ${ }^{3}$ \\ Orcid ID: https://orcid.org/0000-0002-1902-4630
}

RESUMO: Este artigo objetiva analisar o romance Amor de perdição (1862), de Camilo Castelo Branco, focalizando a influência da escola romântica, bem como temas presentes no enredo, como: os relacionamentos familiares e sociais; a religiosidade e a família; o patriarcalismo; e a condição da mulher na sociedade do século XIX, observando como vida e obra do escritor estiveram constantemente entrelaçadas. Uma pesquisa analítica que tem como base primária a obra e como base teórica os estudos de pesquisadores que, de alguma forma, têm em comum, trabalhos que apresentem ideias sobre a obra em questão, como é o caso de Candido (2002); Conche (1998); Genette (1995), dentre outros.

Palavras-chave: Romantismo. Camilo Castelo Branco. Amor de perdição.

ABSTRACT: This article aims to analyze the novel Amor de perdição (1862) (Love of perdition) by Camilo Castelo Branco, focusing on the influence of the romantic school, as well as themes present in the plot, such as: family and social relationships; religiosity and family; patriarchy; and the condition of

\footnotetext{
1 Erika Maria Albuquerque Sousa Graduanda em Letras Português e Literaturas de Língua Portuguesa pela Universidade Estadual do Maranhão - CESC/UEMA. Membro do grupo de pesquisa CNPq: Literatura, Arte e Mídias - LAMID e do Núcleo de Pesquisa em Literatura Maranhense - NUPLIM/ CNPq. Membro do Grupo de Estudos Filhas de Avalon: o feminino em pauta (FECLESC / UECE). Presidente da Liga Interdisciplinar dos Cursos de Letras (LICLE/CESC-UEMA). Bolsista FAPEMA 2021-2022. Representante discente no Colegiado de Letras do Centro de Estudos Superiores de Caxias - CESC/UEMA. Interessa-se pelo estudo de Teoria Literária, Literatura Maranhense, Memória, Autobiografia, Literatura Brasileira, Literatura e meios digitais, Literatura produzida por mulheres. Atuando como pesquisadora desde 2015. Autora do livro "O dilema do taxista: memórias apátridas" (ISBN: 978-65-5869-546-2). E-mail: erikaalbuquerquecescuema@gmail.com
}

\footnotetext{
2 Possui graduação em Letras pela Universidade Federal do Piauí (1989), mestrado em Letras pela Universidade Federal do Piauí (2006) e doutorado em Letras (Ciência da Literatura) pela Universidade Federal do Rio de Janeiro (2014). Atualmente é professora adjunta II da Universidade Estadual do Maranhão Centro de Estudos Superiores de Caxias e professora formadora do Instituto de Educação Antonino Freire, PI. Tem experiência na área de Letras, com ênfase em Ficção e Poesia Brasileiras, atuando principalmente nos seguintes temas: memória, identidade cultural maranhense, Literatura comparada, cultura e poesia popular - cordel, poesia social. E-mail: socorroliteratura10@gmail.com

3 Possui doutorado em Ciência da Literatura-UEMA/UFRJ (2014), mestrado em Teoria da Literatura-UFPE (2002), especialização em Leitura e produção de texto-PUC/MG(2000). Atualmente é Professora Adjunto II, 40h, Diretora dos Cursos de Letras do CENTRO DE ESTUDOS SUPERIORES DE CAXIAS, da UNIVERSIDADE ESTADUAL DO MARANHÃO. Tem experiência na área de Letras, com ênfase em Literatura, Teoria Literária, Literatura Comparada, Literatura Maranhense. Docente do Mestrado em Letras/UEMA. Coordenadora da PósGraduação em Ensino de Língua Portuguesa- CESC. Membro do Núcleo Estruturante do Curso de Letras do CESC/UEMA. Líder do Núcleo de Pesquisa em em Literatura Maranhense-NuPLiM/CNPq-CESC/UEMA. Pesquisadora no Grupo de Estudos Literários Memória e Arte- GELMA/CNPq - CESC-UEMA. Membro do CEP(Conselho de Ética em Pesquisa) da UEMA. Editora-Chefe da Revista de Letras - Juçara, do Departamento de Letras do CESC-UEMA. Coordenadora da Liga Interdisciplinar dos Cursos de Letras-LICLE/CESC-UEMA. Email: sogemorais@gmail.com
} 
women in nineteenth-century society, observing how the writer's life and work were constantly intertwined. It is analytical research that has as its primary basis the work and as its theoretical basis the studies of researchers who, somehow, have works in common that present ideas about the work in question, as the case of Candido (2002); Conche (1998); Genette (1995), among others.

Keywords: Romanticism. Camilo Castelo Branco. Love of Perdition.

\section{Considerações iniciais}

O personagem leitor é um personagem curioso, estranho. Ao mesmo tempo que, inteiramente individual e com reações próprias, é tão terrivelmente ligado ao escritor que na verdade ele, o leitor, é o escritor (LISPECTOR, 2018, p. 80).

O Romantismo foi um movimento literário que se iniciou na Europa, no final do século XVIII. Nascido no contexto da Revolução Francesa, em razão da falência dos impérios feudais, o poder estava sofrendo uma transição, sendo passado das mãos da nobreza para as dos burgueses. A ascensão da classe burguesa provocou uma alteração no público consumidor de literatura, que se tornou mais popular. Em consequência disso, surgiram os primeiros folhetins nos jornais, constituídos de uma literatura assaz sentimentalista, com o intuito de atrair leitores.

Em oposição à objetividade, ao racionalismo e à retomada dos valores clássicos do Arcadismo, o Romantismo foi um movimento marcado pela subjetividade, valorização das emoções, idealismo, individualismo, busca pela liberdade de criação, espiritualidade, valorização do passado e nacionalismo. Assim, o período romântico português divide-se em três momentos: a primeira geração foi marcada por Almeida Garrett e Alexandre Herculano. A segunda geração conhecida como Ultrarromantismo, em que se destacam Camilo Castelo Branco e Soares de Passos. E a terceira geração, representada por Júlio Diniz e João de Deus. De acordo com Álvaro Manuel Machado (1979, p. 26):

[...] as origens do Romantismo são, assim, verdadeiramente europeias, formando-se essa estética da transição chamada Pré-Romantismo como uma teia, a partir de sucessivas depurações de conceitos que desencadeiam um confronto constante de culturas diversas. No desafio aos fundamentos dessas culturas e, portanto, no aprofundar simultâneo desses fundamentos, está a sua mais legítima originalidade. Originalidade suficiente, quanto a mim, para justificar a sua autonomia, quer em relação ao classicismo quer em relação ao romantismo.

A constituição dos ideais românticos foi influenciada por alguns filósofos da época, que serviram como pórtico ao início do movimento, dentre alguns nomes 
destaca-se o filósofo suíço Jean Jacques Rousseau (1712-1778), considerado o precursor do romantismo, idealizador da teoria do "bom selvagem", que postulava ideias como: "o homem é bom por natureza. É a sociedade que o corrompe".

Outros dois filósofos alemães que tiveram influência no movimento romântico foram Johann Gottlib Fichte (1762-1814) e Friedrich Wilhelm Joseph Von Schelling (1775-1854). O primeiro afirmava que o racionalismo era apenas uma parte do intelecto, ao lado de outros aspectos, como experiência, intuição, imaginação, entre outros. O segundo é considerado um dos mais importantes do idealismo alemão pós-Kantiano. Ratificava que "o único conhecimento possível é o que a consciência tem de si própria" (GASPARETTI apud CASTELO BRANCO, 2011. p.14), assim, o único saber relevante era o autoconhecimento, ideia que se relaciona ao individualismo e subjetivismo dos escritores românticos.

Nesse clima de revolução, nasce em Lisboa, em 16 de março de 1825, Camilo Castelo Branco, filho "bastardo" de Manuel Joaquim Botelho Castelo Branco, um aristocrata. Órfão de mãe, e posteriormente de pai, foi criado por parentes e desde cedo, educado informalmente por padres. Formou-se em Direito, mas optou por exercer o jornalismo. Devido ao seu caráter satírico e idealista, teve problemas com políticos, tendo sido agredido fisicamente diversas vezes. Adquiriu matrimônio muito cedo, mas o casamento não durou muito.

Passou a envolver-se com muitas mulheres, dentre elas o caso mais polêmico foi com Ana Plácido, por quem se apaixonou. Ana era casada e para ficarem juntos, teve de raptá-la. Ambos chegaram a ser presos e julgados, foi nessa época que Camilo escreveu seus dois romances mais famosos: Memórias do cárcere e Amor de perdição. Camilo Castelo Branco viveu com Ana até o fim de seus dias. Entrementes, sua vida foi marcada por uma série de adversidades: os filhos, as dificuldades financeiras, a cegueira progressiva, a sífilis. O autor acaba suicidandose com um tiro na cabeça, em $1^{\circ}$ de junho de 1890.

A produção de Camilo Castelo Branco costuma ser classificada pelos críticos como romântica. No entanto, alguns elementos de seu estilo levam outros a afirmar que o autor estaria entre os precursores do Realismo. Ideia essa que poderia ser confirmada por haver muita sátira, ironia e sexualismo em sua obra, aspectos que destoam do romantismo. Todavia, foram diversas as críticas que o autor fez ao movimento realista. No prefácio da quinta edição de Amor de perdição, ele chega a lamentar que os críticos vissem realismo em sua obra: 
O bom-senso público relê isso, compara com aquilo, e vinga-se barrufando com frouxos de riso realista as páginas que há dez anos aljofarava com lágrimas românticas. (...) Se, por virtude da metempsicose, eu reaparecer na sociedade do século XXI, talvez me regozije outra vez ver as lágrimas em moda nos braços da retórica (...). (CASTELO BRANCO, 2011, p. 16).

Cabe ressaltar, que apesar de sua obra possuir traços que divergem da estética romântica, o autor apresenta um estilo novelesco típico do romantismo, com narrativas marcadas pelo sentimentalismo e acontecimentos dramáticos. Além disso, seus finais trágicos são coerentes com as tendências da segunda geração. Destarte, é correto afirmar que seu estilo é essencialmente romântico.

Mediante essas breves explanações sobre vida e obra do autor em questão, França (1993, p. 285) afirma: "Camilo e seus heróis vivem no mesmo universo dramático, de cores intensas, ao mesmo tempo sublimes e sórdidas. O ideal dum programa imaginário e da realidade duma experiência vivida encontra-se unidos e indissociáveis".

Assim, este artigo objetiva analisar o romance Amor de perdição, focalizando a influência da escola romântica, bem como temas presentes no enredo, como: os relacionamentos familiares e sociais; a religiosidade e a família; o patriarcalismo; e a condição da mulher na sociedade do século XIX. Observando, ainda, como vida e obra do escritor estiveram constantemente entrelaçadas.

\section{OBRA}

\subsection{Enredo}

Amor de Perdição é uma novela escrita no período em que seu autor, Camilo Castelo Branco, estava preso na cadeia do Porto, em 1861, segundo o escritor, redigida em apenas 15 dias. Mas a obra só é publicada em 1862 quando Camilo e Ana são libertados. Segundo Alexandre Cabral (1981, p. 38), os anos que se estendem de 1859 a 1862 correspondem a um "período de fraca atividade polemista". O que favoreceu a recepção que a novela teve ao ser publicada em Portugal naquele período.

Considerado pelos críticos como o Romeu e Julieta lusitano, Amor de perdição narra o amor proibido entre Simão Botelho, um jovem temperamental e engajado com os princípios jacobinistas, e Teresa de Albuquerque, exemplo de heroína típica do Romantismo, considerada "mulher-anjo", devota e resoluta em seu 
amor. Não atoa o romance recebe essa comparação com a obra de Shakespeare, uma vez que em muitos detalhes os dois enredos apresentem afinidades, como a perseguição entre as famílias, a morte como consequência e o amor à primeira vista.

Pode-se, também, estabelecer uma linha de comparação entre o romance de Camilo Castelo Branco com a obra de Machado de Assim: Dom Casmurro, Simão e Teresa são vizinhos, assim como Capitu e Bentinho. O que os difere são os finais definidos por cada autor. Em Amor de perdição, os dois mantêm um namoro discreto e silencioso através das janelas e vivem um amor puro e virtuoso, que redime os erros e transforma suas personalidades. Enquanto em Dom Casmurro, apesar dos personagens, Bento e Capitolina, conseguirem casar-se seus finais serão definidos por eles próprios, sem intervenção dos familiares. Sobre as situações comuns nos três romances citados, Samira Nahid de Mesquita (2006, p.29) afirma:

No romantismo, por exemplo, - movimento dentro do qual "nasceu" o gênero romance - embora as preocupações de ordem social existissem, predominaram os enredos de amor. Toda narrativa se construía a partir do encontro de dois jovens, inexperientes no amor, que se apaixonavam à primeira vista. Todas as situações que se sucedem ao primeiro encontro vão ser criadas pela luta obstinada do par amoroso para realizar o seu amor. Os obstáculos a vencer são geralmente as desigualdades sociais, a autoridade paterna, um rival poderoso, o mistério da origem de um dos apaixonados, entre outros. Na conclusão, há sempre a vitória do amor ou da morte, esta sob a forma de loucura ou de entrada para um convento formas de "morrer" para o mundo.

Em concordância com a citação supracitada, apesar da afeição de Simão e Tereza ser marcada pela pureza dos amantes, será responsável por uma série de tragédias. A novela é caracterizada pelo drama e pela fatalidade, e os personagens são "mártires do amor", que o consideram impossível e o mais sublime de todos e, no sofrimento, encontram um sentido profundo para a existência. Na obra, em questão, de Camilo Castelo Branco, Amor de Perdição, tudo é passional, e a concepção do amor é marcada pela transcendência, como uma espécie de destino fatal do qual não se pode fugir, que domina, orienta e define a vida dos personagens.

\subsection{Personagens}

A presença das personagens (protagonistas, secundários e antagonistas) nas obras românticas é essencial para a configuração maniqueísta do enredo, tendo 
uma influência direta ou indiretamente no destino das personagens. Os heróis são descritos de forma completa apresentando-os como "bons", enquanto nos antagonistas, ou maus, não se encontram muitas qualidades descritas. O herói romântico de Amor de perdição é Simão, descrito, ainda, na introdução como:

Simão António Botelho, que assim disse chamar-se, ser solteiro e estudante na universidade de Coimbra, natural da cidade de Lisboa (...) filho de Domingos José Correia Botelho e de D. Rita Preciosa Caldeirão Castelo Branco; estatura ordinária, cara redonda, olhos castanhos, cabelo e barba preta, vestido com jaqueta de baetão azul, colete de fustão pintado e cala de pano pedrês (CASTELO BRANCO, 2011, p. 27).

Antonio Candido (2002, p. 71) em sua obra $A$ personagem de ficção esquematiza alguns modelos deixados pelos romancistas que explicam a criação das personagens dentro do enredo. Em sua primeira denominação, o autor cita as personagens transpostas com relativa fidelidade de modelos dados ao romancista por experiência direta, - seja interior, seja exterior. No primeiro caso, é a personagem projetada, em que o escritor incorpora a sua vivência, os seus sentimentos. Já no segundo caso da experiência exterior é o da transposição de pessoas com as quais o romancista teve contato direto.

Diante de tal explanação é possível inferir que Castelo Branco se utiliza de tais técnicas ao escrever o seu romance, aqui, analisado. Pode-se traçar alguns paralelos entre vida e obra do escritor ao analisar os protagonistas do romance Amor de Perdição, em que o autor toma como pórtico sua vida e transforma-a em história. Na figura de Simão, há um espelho entre ficção e realidade, podendo esse ser o próprio autor, Camilo. Na figura de Teresa, Ana, sua amada.

Quanto à personalidade do jovem herói, Simão é como muitos outros, desafia o mundo à guerra contra a tradição, a religião, a nobreza e a monarquia. Mas tudo muda quando se apaixona por Teresa, distancia-se da vida conturbada de Viseu; torna-se caseiro; cumpre os seus deveres de estudante; passeia pelo campo, procurando o espaço natural, em detrimento do espaço social. No entanto, revela-se novamente rebelde quando sua amada, Teresa, é obrigada a casar-se com o primo Baltasar. Simão, para defender o código de honra, acaba matando Baltasar e sendo condenado a cumprir dez anos de pena, em Portugal, na cadeia da cidade de Viseu.

Duas personagens que atuam como heroínas na obra são Teresa e Mariana; com suas particularidades, as moças causam grande rebuliço no enredo, 
apresentando o contraste existente em suas personalidades. Teresa Albuquerque é apresentada como um tipo característico das heroínas românticas: amorosa, angelical e vítima das decisões impostas pelo patriarcalismo da época. Teresa é objeto de amor de Simão, sendo por ele correspondida; mesmo digna, se apresenta frágil ao longo da trama. Como referência à Teresa, diz o narrador:

(...) É mulher varonil, tem força de caráter, orgulho fortalecido pelo amor, despego das vulgares apreensões, se são apreensões a renúncia que uma filha faz do seu alvedrio às imprevidentes e caprichosas vontades de seu pai. (...) Teresa adivinha que a lealdade tropeça a cada passo na estrada real da vida, e que os melhores fins se atingem por atalhos onde não cabem a franqueza e a sinceridades. Estes ardis são raros na idade inexperta de Teresa; mas a mulher do romance quase nunca é trivial, e esta de que rezam os meus apontamentos era distintíssima (...). (CASTELO BRANCO, 1983, p. 122).

Teresa seria, portanto, uma personagem plana, conforme esclarece Antonio Candido (2002, p. 62):

As personagens planas eram chamadas temperamentos (humours) no século XVII, e são por vezes chamadas tipos, por vezes caricaturas, na sua forma mais pura, são construídas em torno de uma única ideia ou qualidade; quando não há mais de um fator neles, temos o começo de uma curva em direção a esfera.

Já Mariana caracteriza-se como personagem esférica, pois "se reduz essencialmente ao fato de ter três, e não duas dimensões; de ser, portanto, organizada com maior complexidade e, em consequência, capaz de nos surpreender" (CANDIDO, 2002, p. 63). Sendo descrita como mulher da aldeia, forte, que considera colocar a felicidade de Simão acima da própria, sem esperar recompensa. Apesar de amá-lo, Mariana faz de tudo para que os dois enamorados (Teresa e Simão) sejam felizes. Submetendo-se a diversas situações, dentre elas: levando cartas, emprestando dinheiro e até mesmo cuidando de Simão. Mariana representa a abnegação do amor como pode ser ilustrado no trecho:

Desde este dia, um secreto júbilo endoidecia o coração de Mariana. Não inventemos maravilhas de abnegação. Era de mulher o coração de Mariana. Amava como a fantasia se compraz de idear o amor duns anjos que batem as asas de baile em baile, e apenas quedam o tempo preciso para se fazerem ver e adorar a um reflexo de poesia apaixonada. Amava, e tinha ciúmes de Teresa, não ciúmes que se refrigeram na expansão ou no despeito, mas infernos surdos, que não rompiam em lavareda aos lábios, 
porque os olhos se abriam prontos em lágrimas para apagá-la. Sonhava com as delícias do desterro, porque voz humana alguma não iria lá gemer à cabeceira do desgraçado (...). (CASTELO BRANCO, 1983, p. 279).

Outro personagem que figura como secundário é Baltasar Coutinho, primo de Teresa, descrito como um covarde, vaidoso, interesseiro, e cínico, sendo o total oposto de Simão. Por conta da vaidade de Baltasar, ele acaba não aceitando o amor de Simão e Teresa, e utilizando-se de seu espírito manipulador, faz de tudo para impedir a união do jovem casal apaixonado. Baltazar é o que Antonio Candido (2002) chamou por personagem construída em torno de um modelo, direta ou indiretamente conhecido, mas que apenas é um pretexto básico, um estimulante para o trabalho de caracterização, que explora ao máximo as suas virtudes por meio da fantasia, quando não as inventa de maneira que os traços da personagem resultando não poderiam, logicamente, convir ao modelo. Diante disso:

\begin{abstract}
Ao lado de tais tipos de personagens temos ainda àquelas cuja origem pode ser traçada mais ou menos na realidade, é preciso assinalar aquelas cujas raízes desaparecem de tal modo na personalidade fictícia resultado, que, ou não têm qualquer modelo consciente, ou os elementos eventualmente tomados à realidade não podem ser traçados pelo próprio autor. Em tais casos, as personagens obedecem a uma certa concepção de homem, a um impulso indefinível, ou quaisquer outros estímulos de base, que o autor corporifica, de maneira a supormos uma espécie de arquétipo que, embora nutrido da experiência de vida e da observação, é mais interior do que exterior (CANDIDO, 2002, p. 73).
\end{abstract}

Como é o caso de João da Cruz, pai de Mariana, torna-se um protetor de Simão, ajudando-o em cada situação que o jovem se envolvida. Ajuda-o com estratégias e conselhos. Simão e João da Cruz são bastante parecidos: são ambos bondosos, corajosos e gratos.

Manuel Botelho é também uma personagem figurante na ação, irmão mais velho de Simão. No início do livro, tem 22 anos, e frequenta o segundo ano jurídico. Um grupo de personagens existentes na obra é o das freiras, o autor utiliza-se delas como uma crítica à corrupção e hipocrisia da sociedade onde Teresa e Simão estavam presos. D. Rita Preciosa é uma personagem secundária, plana, e mãe do protagonista, Simão Botelho. Representa a convencionalidade do sentimento materno, e age mais por obrigação familiar que por afeição: ajuda Simão, ao pagar o ferrador, não por amor de mãe, mas porque esse era o seu papel. 
Ritinha é uma personagem figurante, sendo esta a irmã mais nova de Simão. Domingos Botelho, pai de Simão e Tadeu de Albuquerque, pai de Teresa, são duas personagens secundárias que se assemelham uma à outra, pois ambas representam o poder do patriarcado na obra. São personagens planas, pois desde o início se opõem à relação dos seus filhos e, mesmo depois das suas mortes, os dois homens continuam inimigos e não fazem as pazes.

\subsection{Espaço, tempo e foco narrativo}

Pode-se narrar o tempo, o próprio tempo, o tempo como tal e em si? ${ }^{4}$

A trama se passa no século XIX, em Portugal, cidade de origem de Camilo Castelo Branco. Ao longo da narrativa podemos identificar três locais específicos descritos: a cidade de Viseu, aonde Simão é levado para cumprir uma pena de dez anos pelo assassinato do primo de Teresa, Baltazar. O Convento de Monchique, no Porto, local para aonde Teresa é levada logo após a estada no Convento de Viseu. E o Porto, onde finda-se a narrativa com a morte das personagens: Simão, Teresa e Mariana.

O narrador de Amor de perdição se mostra atento aos detalhes que complementam a narrativa (com referências históricas e literárias) e habilidoso, induzindo o leitor a exaltar-se quando da narração dos fatos mais tensos, a acompanhar as inúmeras digressões e a comover-se e revoltar-se com o destino das personagens. Apresentando-se como heterodiegético, segundo Carlos Reis e Ana Cristina Lopes (1980, p. 254-5), seria aquele que "designa uma particular ação narrativa: aquela em que o narrador relata uma história à qual é estranho, uma vez que não integra nem integrou, como personagem, o universo diegético em questão". Onisciente na maior parte do tempo, algumas vezes o narrador toma a posição de quem ignora informações, como no início do capítulo 6:

Às dez horas e meia da noite daquele dia, três vultos convergiram para o local, raro frequentado, em que se abria a porta do quintal de Tadeu de Albuquerque. (...) Dos três vultos, havia um cujas palavras eram ouvidas em silêncio e sem réplica pelos outros. Dizia ele a um dos dois (...). (CASTELO BRANCO, 1983, p. 141).

\footnotetext{
4 MANN, Thomas. A montanha mágica. 3.ed. Rio de Janeiro, Nova Fronteira, 1980.
} 
Sánchez Noriega (2000, p. 89) identifica, ainda, o narrador heterodiegético como a personagem que relata a história na qual não participa que está inserida na narração mais ampla, ou seja, é o narrador de outro nível face ao nível principal, exemplificando a narração metadiegética. Este tipo de narrador pode narrar a totalidade da história, ainda que possa aparecer apenas num prólogo, numa introdução, em voz off, não deixando de constituir um exemplo de narrador intradiegético.

Há outras ocasiões em que o narrador aparece em primeira pessoa: "Pois eu já Ihes fiz saber, leitores, pela boca de mestre João, que o filho do corregedor não tinha dinheiro. Agora lhes digo que era em dinheiro que ele cismava, quando Mariana the trouxe o caldo rejeitado. A meu ver, deviam atribulá-lo estes pensamentos (...)" (CASTELO BRANCO, 1983, p. 179).

Para Genette (1995, p. 23-25), a história diz respeito à diegese, isto é, ao significado, ao conteúdo narrativo que pode ser real ou imaginário. A história é composta pela sucessão de acontecimentos. Melhor ainda, ela constitui a "matériaprima" da narrativa. Há situações em que o narrador sai da dimensão diegética para explicar o que acontecerá em certos capítulos ou para falar sobre o texto, tomando a posição de organizador. Como exemplo, o último parágrafo do capítulo 2:

(...) No seguinte capítulo se diz minuciosamente a peripécia que forçara a filha de Tadeu de Albuquerque a escrever aquela carta de pungentíssima surpresa para o acadêmico, convertido aos deveres, à honra, à sociedade e a Deus pelo amor. (CASTELO BRANCO, 1983, p. 111).

Portanto, comprova-se que a escrita de Camilo é plural, carregada de diálogos, digressões e interações entre narrador e leitor, possibilitando o acompanhamento dos fatos descritos no enredo, através das diversas perspectivas apresentadas.

\section{Temas do enredo}

\subsection{0 amor, o triângulo amoroso}

O mote do enredo se dá a partir da existência de dois triângulos amorosos, que figuram toda a trama. Uma das relações é entre Simão, Teresa e Mariana, sendo o amor dos dois primeiros recíproco, enquanto Mariana não é correspondida. 
segundo triângulo amoroso é composto por Teresa, Simão e Baltasar, esse último, aqui, não é correspondido.

Apesar da existência das quatro personagens envolvidas no enredo, o interesse e foco narrativo tomam como pórtico somente a união de Teresa e Simão. Baltasar figurando como antagonista e Mariana como uma segunda heroína, ao lado de Teresa, cuja marca é a abnegação da realização amorosa em prol da felicidade de seu amado, Simão.

O final do romance se caracteriza com a morte trágica de todos os personagens, uma marca presente do romantismo em que podemos identificar o sentido do título: o amor tendo como consequência a perdição de todos os envolvidos.

\subsection{0 romance da segunda geração romântica}

A segunda geração do Romantismo comumente conhecida como Ultrarromantismo, é marcado pela exaltação exagerada da subjetividade, da idealização do amor e da natureza. Moisés (1980, p. 180) afirma: "sempre o amor impossível e superior, ou marginal aos preconceitos sociais, pois brota do mais fundo da carne e da alma, levando ao devaneio os apaixonados com as promessas de duma bem-aventurança via de regra malograda". Com uma poesia egocêntrica, sentimentalista carregada de tristeza e desilusão, os pensamentos pessimistas compõem total descrença pela vida, o que gerou uma obsessão pela morte entre os escritores comuns da época.

Desta maneira, o amor passou a ser o centro da produção literária do Ultrarromantismo, caracterizado pelo aprofundamento assaz trágico, em que o eulírico se encontra numa constante luta para alcançar a realização amorosa idealizada. Assim, na maioria dos casos tinha-se um amor entendido como impossível, surgia então o profundo sentimento de melancolia e o escapismo através da morte. José de Nicola (1999, p. 143) assevera: "trata-se, afinal, de promover o amor à categoria do sagrado, do incomensurável com a razão e com as normas morais correntes (...). Há sempre uma grandeza trágica de paixões e situações, os personagens são penitentes do amor".

Mediante esse sentimento avassalador é possível encontrar resquícios autobiográficos dos autores. Na obra de Camilo Castelo Branco não é diferente, pois 
Amor de perdição foi escrito durante sua estada na prisão, motivada por adultério. Portanto, pode-se perceber que os personagens desse segundo momento do romantismo estão fadados a alimentar um amor forte e doloroso.

\subsection{Os relacionamentos familiares e o patriarcalismo}

Camilo Castelo Branco representa bem a sociedade portuguesa da época em que ele vivia, século XIX, na obra aqui retratada. Reis e Pires observam: "a propósito ainda do Amor de Perdição, é importante salientar que a situação paradigmática dos amores contrariados transmite a imagem da estrutura social da época" (REIS; PIRES, 1999, p. 225). Era comum a presença do patriarcalismo na tomada de decisões, os pais contrariarem os amores dos filhos e se sentirem à vontade para escolherem com quem eles iriam casar-se.

Dessa forma, a novela Amor de perdição atende ao convencionalismo da época, demonstrado na estrutura da obra, sem muitas descrições e dando ênfase ao diálogo. Sobre isso, Coelho (2001, p. 467) diz que:

O conservantismo de Camilo começa por denunciar-se na audácia apenas relativa (de acordo aliás com as características do meio português) com que põe, na novela, o problema do casamento desigual. (...) Camilo, aliás, não costuma separar por desigualdades excessivas os amantes cuja causa defende.

Camilo Castelo Branco dependia financeiramente de suas obras, e por esse motivo não poderia escrever sem pensar em agradar. $O$ autor, então, sabia manipular bem suas obras para que a sociedade portuguesa do século XIX não se sentisse atingida com o que estava sendo relatado. Para isso, o escritor investiu em temas que agradavam sobremaneira todos os tipos de leitores, assim, para escrever para os pais conservadores e patriarcalistas, toma como mote a briga entre as duas famílias descritas no romance.

Referindo-se à briga, esta acaba sendo a impossibilidade da união entre as personagens Teresa e Simão, pois os pais de ambos acabam se tornando inimigos após uma discussão, e suas famílias (Família Albuquerque x Família Botelho) passam a ser rivais.

Ao longo de toda a narrativa é possível observar críticas à sociedade e seus valores, dentre elas uma das mais explícitas refere-se à religião, sendo diretamente 
à vida nos conventos. Camilo critica os santuários da época, que não eram como se imaginavam: cheios de purezas e fraternidade, pelo contrário, apresentavam-se antros de egoísmo, cobiça, gula e intrigas: “(...) a escrivã entrou a tempo que Teresa, com as mãos abertas sobre a face, dizia em si: "Um convento, meu Deus! Isto é que é um convento!" (CASTELO BRANCO, 1983, p. 165).

Outro trecho que chama atenção pela ironia e crítica do escritor sobre a casta vida dos conventos:

Não delongaremos esta amostra do evangélico e exemplar viver do convento onde Tadeu de Albuquerque mandara sua filha a respirar o puríssimo ar dos anjos, enquanto se lhe prepara crisol mais depurador dos sedimentos do vício no convento de Monchique (CASTELO BRANCO, 1983, p. 168).

Outro valor retratado no romance se dá com a fala do ferreiro, João da Cruz, quando trata das mulheres e o casamento:

(...) Paixões, que as leve o diabo, e mais quem com elas engorda. Por causa de uma mulher, ainda que ela seja filha do rei, não se há de um homem botar a perder. Mulheres há tantas como a praga, e são como as rãs do charco, que mergulha uma, e aparecem quatro à tona da água. Um homem rico e fidalgo como vossa senhoria, onde quer topa uma com um palmo de cara como se quer, e um dote de encher o olho. Deixe-a ir com Deus ou com a breca, que ela, se tiver de ser sua, à mão lhe há de vir dar, e tanto faz andar pra trás como pra diante, é ditado dos antigos (CASTELO BRANCO, 1983, p. 199).

Diante disso, o romance camiliano visa representar a vida dos personagens, unindo o real à ficção, principalmente, no que diz respeito às mulheres. Essas que não poderiam realizar seus ideais românticos por estarem presas a uma sociedade que delas cobrava submissão ao homem. O autor acaba direcionando sua narrativa para ganhar o reconhecimento delas.

\subsection{A condição da mulher na sociedade do século $X I X$, representada no romance}

Segundo Conche "o verdadeiro amor não é puramente sentimental. Ele não deixa de fora a razão e a vontade. Empenha todas as forças do homem, mas deixando-o livre, senhor de si, não governado por seu amor, mas governando seu amor" (1998, p. 9). Mediante essa definição filosófica de Conche, a obra apresenta duas personagens que veem seus destinos fugindo de suas perspectivas por uma 
série de questões impostas pela sociedade. Teresa e Mariana são duas heroínas românticas que encontram oposições em suas personalidades, mas dispõem de algo em comum: as duas amam Simão Botelho. Governadas por esse sentimento, fogem a definição de amor descrita acima por Conche.

Ainda no século XIX, a mulher era considerada um ser frágil e emotivo. Neste sentido, para atender às exigências da época, Camilo Castelo Branco descreve Teresa como uma "menina de 15 anos, rica, herdeira, regularmente bonita e bemnascida. [...] Não ficara ela incólume da ferida que fizera no coração do vizinho: amou-o também" (CASTELO BRANCO, 2011, p. 16). A jovem representa a clássica heroína romântica, uma moça rica que não se submete à vontade do pai, estando disposta a renunciar tudo para ficar com seu amado, Simão. Ratifica-se, nessa descrição, a primeira contestação do fato de que a mulher deveria estar sempre às ordens do homem.

Sobre isso Nietzsche, ao afirmar que "conceber a mulher como 'posse' como propriedade a manter sob sete chaves, como algo destinado a servir e que só então se realiza" (NIETZSCHE, 2005, p. 143) representa a situação imposta à mulher submissa ao homem. Teresa quebra essa ideologia quando não aceita o casamento arranjado por seu pai e como forma de punição, é levada para um convento.

Por outro lado, Mariana é descrita como forte, mulher da aldeia, que abre mão do seu amor pela felicidade de terceiros: "moça de 24 anos, formas bonitas, um rosto belo e triste" (CASTELO BRANCO, 2011, p. 29). Apesar de seus traços maduros, de mulher mais velha, seu olhar melancólico, ressalta sua essência romântica através dos sentimentos mais obscuros. Diferentemente de Teresa, Mariana não precisou exercer o papel de moça rebelde, pois seu pai deixava claro a todos que respeitava a vontade da filha de não casar.

Destarte, ainda sobre o amor, Conche diz que ele "não tem outro inimigo além da morte" (1998, p. 9), justificando o fim encontrado pelas personagens Teresa e Mariana. A primeira morre após um longo tempo longe de seu amado, por consequência de uma doença, e a segunda, ao ver Simão morto e jogado ao mar, pula ao seu encontro. Exemplo de que o amor leva ao escapismo através da morte.

\section{Considerações finais}

Através da novela de Camilo Castelo Branco Amor de perdição foi possível inferir-se algumas breves análises sobre o período romântico em que a obra foi 
produzida, assemelhando-se com registros autobiográficos da história do autor; bem como acompanhar o contexto de sua produção, a segunda fase do modernismo em Portugal, observando como a escrita camiliana se impõe diante da sociedade do século XIX.

Através da narrativa, conhece-se os lugares de Portugal, a religiosidade, 0 poder do patriarcalismo e a condição da mulher naquela sociedade. Os fatos apresentados por um narrador heterodiegético influenciou na boa recepção do romance tanto em Portugal como no Brasil, abordando temas sensíveis de maneira irônica e singular. Amor de perdição é considerado um clássico do período ultrarromântico e neste breve ensaio tentou-se ratificar ainda mais a grandiosidade de Camilo Castelo Branco.

\section{REFERÊNCIAS}

CABRAL, Alexandre. Polémicas de Camilo (volume I). Lisboa: Livros Horizonte, 1981.

CASTELO BRANCO, Camilo C. Amor de perdição. Lisboa: Comunicação, 1983.

BRANCO, Camilo C. Amor de perdição. - 3.ed. - São Paulo: Martin Claret, 2011. (Coleção obra-prima de cada autor; 15).

CANDIDO et al.. A personagem de ficção. São Paulo: Editora Perspectiva, 2002.

COELHO, Jacinto do Prado. Introdução ao Estudo da Novela Camiliana. 3. ed. Lisboa: Imprensa Nacional-Casa da Moeda, 2001.

CONCHE, Marcel. A análise do amor e outros temas. São Paulo: Martins Fontes, 1998.

FRANÇA, José Augusto. O Romantismo em Portugal: estudo de factos socioculturais. Lisboa: Livros Horizonte, 1993.

GENETTE, G. Discurso da narrativa. Lisboa: Vega, 1995.

LISPECTOR, Clarice. Todas as crônicas/Clarice Lispector; prefácio de Marina Colasanti; Organização de Pedro karp Vasquez; Pesquisa textual de Larissa Vaz. $1^{\circ}$ ed. - Rio de Janeiro: Rocco, 2018.

MACHADO, Álvaro Manuel. As origens do Romantismo em Portugal. 1a ed. Lisboa: ICALP. 1979.

MESQUISTA, Samira Nahid de. O enredo. - 4.ed. - São Paulo: Ática, 2006. 
MOISÉS, Massaud. A literatura portuguesa. São Paulo. Cultrix, 1962.

NICOLA, José de. Literatura portuguesa: das origens aos nossos dias. São Paulo: Scipione, 1999.

NIETZSCHE, F. Além do bem e do mal: prelúdio a uma filosofia do futuro. São Paulo: Companhia das Letras. 2005.

NORIEGA, José Luis Sánchez, De la literatura al cine. Barcelona: Paidós, 2000.

REIS, Carlos; PIRES, Maria da Natividade. História Crítica da Literatura Portuguesa: o Romantismo. (volume V). 2. ed. Lisboa; São Paulo: Verbo, 1999.

REIS, Carlos; LOPES. Ana Cristina. Dicionário de Narratologia. Coimbra: Almedina, 1980. 